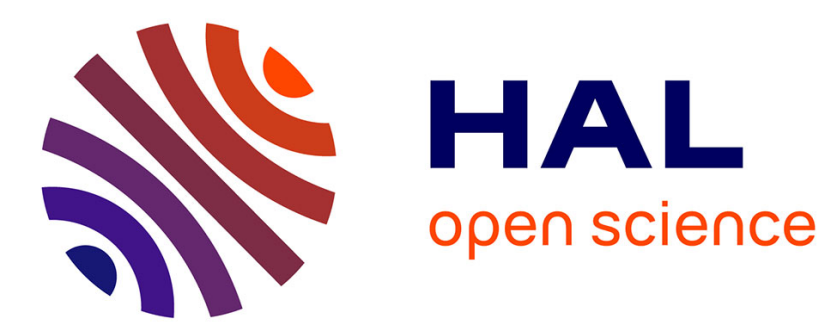

\title{
HIGH STRAIN, HIGH STRAIN-RATE DEFORMATION OF COPPER
}

\author{
M. Meyers, L. Meyer, K. Vecchio, U. Andrade
}

\section{To cite this version:}

M. Meyers, L. Meyer, K. Vecchio, U. Andrade. HIGH STRAIN, HIGH STRAIN-RATE DEFORMATION OF COPPER. Journal de Physique IV Proceedings, 1991, 01 (C3), pp.C3-11-C3-17. 10.1051/jp4:1991302 . jpa-00249893

\section{HAL Id: jpa-00249893 https://hal.science/jpa-00249893}

Submitted on 1 Jan 1991

HAL is a multi-disciplinary open access archive for the deposit and dissemination of scientific research documents, whether they are published or not. The documents may come from teaching and research institutions in France or abroad, or from public or private research centers.
L'archive ouverte pluridisciplinaire HAL, est destinée au dépôt et à la diffusion de documents scientifiques de niveau recherche, publiés ou non, émanant des établissements d'enseignement et de recherche français ou étrangers, des laboratoires publics ou privés. 
Colloque C3, suppl. au Journal de Physique III, Vo1. 1, octobre 1991

\title{
HIGH STRAIN, HIGH STRAIN-RATE DEFORMATION OF COPPER
}

\author{
M.A. MEYERS ${ }^{*}$, L.W. MEYER ${ }^{*}$, K.S. VECCHIO* and U. ANDRADE ${ }^{*}$ \\ "Department of Applied Mechanics and Engineering Sciences, \\ University of California, San Diego, La Jolla, CA 92093-0411. \\ U.S.A \\ ** Fraunhofer Institut für Angewandte Materialforschung, \\ Bremen, Germany
}

\begin{abstract}
Shock-hardened polycrystalline copper was subjected to high strains $(\gamma \sim 5)$ at high strain rates $\left(\dot{\gamma} \sim 10^{4} \mathrm{~s}^{-1}\right)$ using a stepped specimen in a Hopkinson bar. Microstructural analysis by transmission electron microscopy revealed that the highly deformed region consisted of very small grains $(\sim 0.1 \mu \mathrm{m})$ with a low dislocation density. These results are discussed in terms of dynamic recrystallization, which is enabled by the adiabatic temperatures rise associated with plastic deformation. This dramatic microstructural refinement enables a thermomechanical response that may lead to a stable plastic deformation in tension.
\end{abstract}

\section{1. - Introduction.}

The very high strains undergone by copper jets in shaped charges have been attributed to a lateral inertia by Grady $/ 1 /$, Fressengeas and Molinari $/ 2 /$, and Romero $/ 3 /$. The X-ray diffraction experiments by Jamet $/ 4$, $5 /$ have conclusively shown that the jet is solid in aluminum, and at least partially solid (the surface was crystalline) for copper. Recently, Chokshi and Meyers /6/, and Meyers et al. $7 /$ proposed that dynamic recrystallization plays a key role in the stability of the jet. The recovery and observation of jet and slug fragments, as has been demonstrated by heat transfer calculations by Meyers et al. $7 /$, cannot yield reliable results because the cooling times are orders of magnitude larger than the deformation times. In the research reported herein a special experimental procedure is described for capturing the microstructure developed at high strains and strain rates. The experimental method subjects a thin $(\sim 200 \mu \mathrm{m})$ region of copper to very high strains $(\gamma \sim 5)$ at high strain rates $\left(\dot{\gamma} \sim 10^{4} s^{-1}\right)$. Upon completion of deformation, the region is cooled to one-half the original temperature change in less than one millisecond.

\section{2. - Experimental Techniques.}

Copper was shock hardened by planar impact using an explosively accelerated flyer plate in the set-up shown schematically in Figure 1. The detonator initiates a plane wave generator, which in turn, initiates simultaneously the top surface of a cylindrical charge of PBX 9404 explosive. The explosive charge accelerates a flyer plate ( $4.7 \mathrm{~mm}$ thick stainless steel) which impacts the system containing a copper disk; lateral and bottom momentum traps were provided to ensure that one single compressive pulse traversed the specimen. Velocity pins were used to determine the impact velocity, which was equal to $2,200 \mathrm{~m} / \mathrm{s}$. This velocity corresponded to a pressure, in the copper disk, of approximately $55 \mathrm{GPa} / 8 /$.

Cylindrical and hat-shaped specimens were machined from the shocked hardened copper. The cylindrical specimens had dimensions of $6 \mathrm{~mm}$ diameter and $5 \mathrm{~mm}$ length. The hat-shaped specimens, developed by Hartman et al /9/, are schematically shown in Figure 2. The design generates high strains in the shear concentration region marked in Figure 2. A spacer ring was used to establish the maximum plastic deformation. Both cylindrical and hat-shaped specimens were tested on a compression Hopkinson bar. 


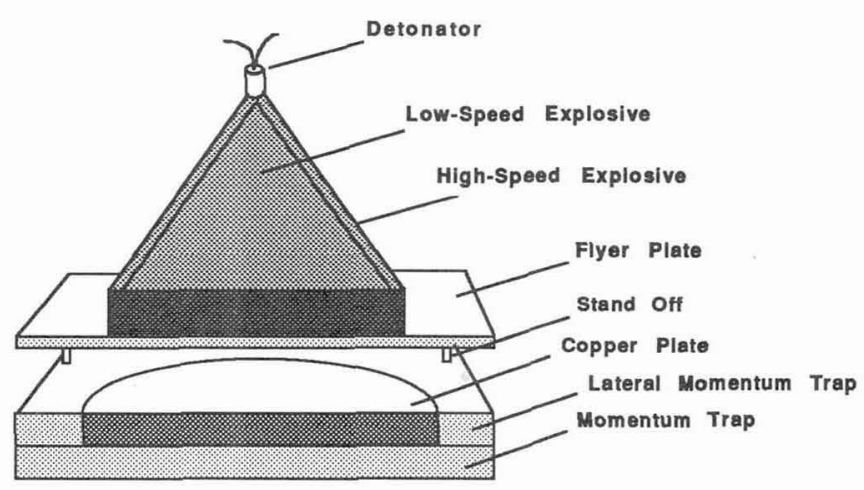

Fig. 1 Experimental set-up for shock hardening copper.

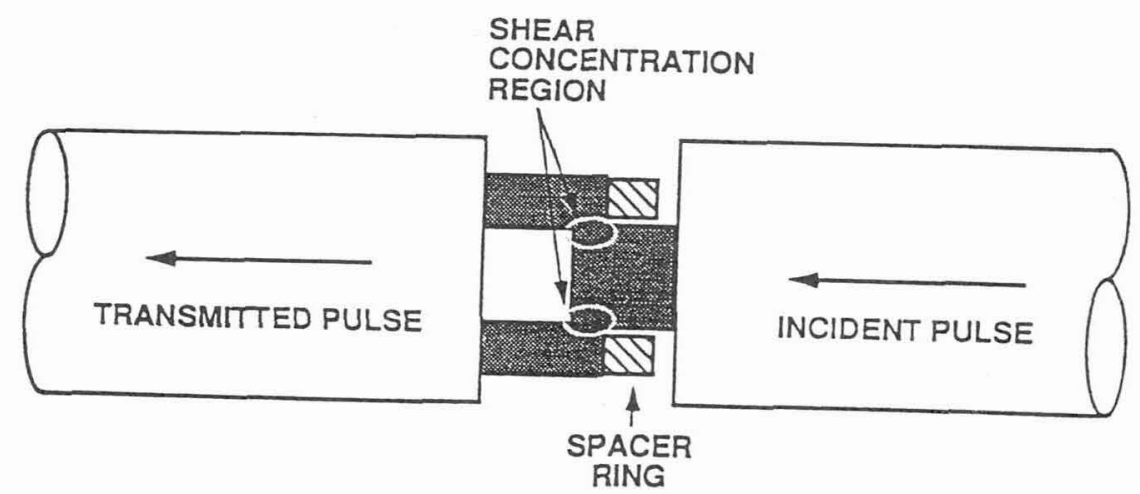

Fig. 2 Hat-shaped specimen used to generate high shear strains at high strain rates $\left(\dot{\gamma} \approx 10^{4} \mathrm{~s}^{-1}\right)$ in Hopkinson pressure bar.

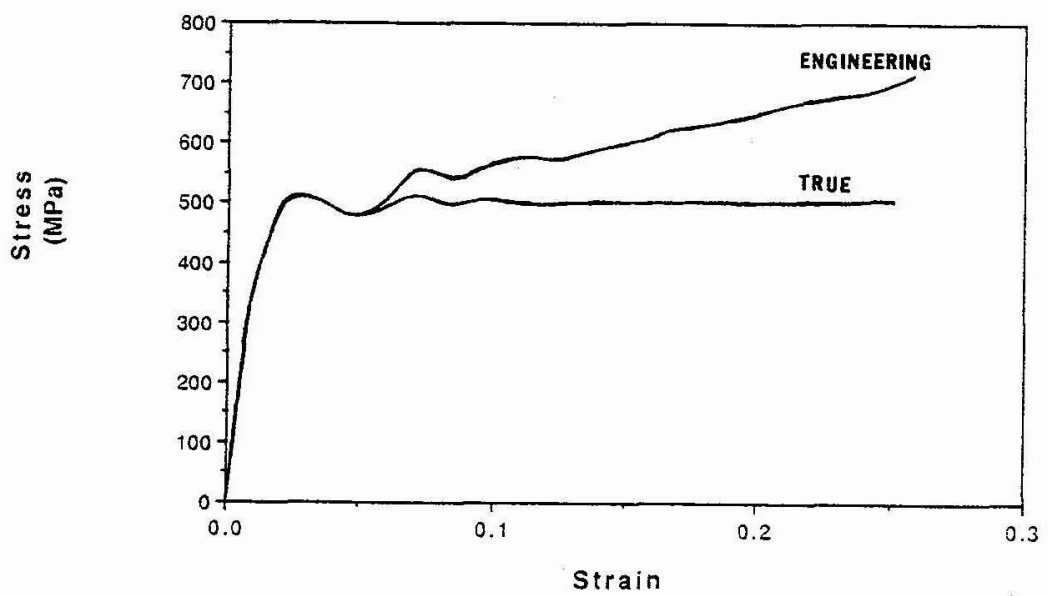

Fig. 3 Compressive stress-strain response of shock hardened copper at strain rate of $4 \times 10^{3} \mathrm{~s}^{-1}$. 
Specimens for transmission electron microscopy were prepared by sectioning the area that underwent high shear strains, cutting $3 \mathrm{~mm}$ disks, dimpling them on the shear concentration region and jet-polishing them in a solution of $20 \%$ nitric acid and $80 \%$ methanol at $-20^{\circ} \mathrm{C}$. A Philips CM-30 transmission electron microscope operated at $300 \mathrm{kV}$ accelerating potential was used to characterize the microstructural deformation evolution surrounding and within the shear bands.

\section{3. - Results and Discussion}

The shock hardened copper exhibited a much higher yield stress than its original value at low strain rate. Figure 3 shows the stress-strain curve of the material. There is no work hardening after a strain of 0.03 . The flow stress for annealed copper is approximately $200 \mathrm{MPa}$ at the same strain rate, and exhibits normal work hardening. The objective of shock hardening the copper prior to the mechanical tests was to more closely simulate the condition of a metal undergoing high strain, high strain-rate plastic deformation in a shaped charge jet or explosively forged projectile. The detonation of the explosive in intimate contact with the metal generates, in the latter, a shock wave of high amplitude which significantly modifies its thermomechanical response.

Figure 4 shows the high shear strain region in the hat-shaped specimen after a shear strain of 5 . One cannot distinguish any features within this region. The grain structure of the copper can be seen. outside of the shear band, containing deformation twins characteristic of shock-loaded copper $/ 10 \%$.

Observations by transmission electron microscopy enabled clear identification of the dark shear areas in Figure 4. The sequence of transmission electron micrographs given in Figure 5 shows the evolution of the microstructure as a function of the imposed strains and temperature excursion. Outside of the high strain region the microsctructure is typical of shock-hardened copper. Profuse dislocations are seen in Fig. 5(a), although no deformation twins were imaged. Figure 5(b) shows the rearrangement of these dislocations into elongated cells with sub-boundaries separating them. The misorientation between adjacent subgrains is approximately $10^{\circ}$; the insert in Figure $5(\mathrm{~b})$ shows, marked by arrows, two diffraction spots. As the shear band area is approached further, a gradual refinement of the microstructure is observed (Fig. 5(c)); these elongated features eventually break down, leading to a microcrystalline structure as the prominent feature in the center of the shear concentration area (Fig. 5(d)). The continuous rings of diffraction spots verify that these micrograins are oriented in all directions. The dislocation density within these micrograins is quite low, and the diameter of these grains is approximately $0.1 \mu \mathrm{m}$. Thus, intense plastic deformation under quasi-adiabatic conditions leads to a reduction in grain size from $\sim 50 \mu \mathrm{m}$ to $\sim 0.1 \mu \mathrm{m}$.

Dynamic recrystallization is a well-known mechanism of microstructural modification; it is schematically shown in Fig. 6 . As the material is plastically deformed, at a sufficiently high temperature $\left(>0.5 \mathrm{~T}_{\mathrm{m}}\right)$, new defect-free grains nucleate and grow within the deforming grains. As a direct consequence, the microstructure becomes refined. The rates of nucleation and growth establish the steadystate grain size. Sandstrom and Lagneborg /11/ and Derby and Ashby /12/ proposed theories for dynamic recrystallization that predict the recrystallized grain size as a function of strain rate. Both theories predict the relationship $d_{S S} \propto \ddot{\varepsilon}^{-1 / 2}$ where $d_{S S}$ is the steady-state recrystallized grain size and $\dot{\varepsilon}$ is the strain rate. This refinement in grain size can profoundly affect the mechanical response of the deforming materials. Temporary superplasticity was proposed by Baudelet $/ 13 /$ for a $\mathrm{Cu}-\mathrm{P}$ alloy. This superplasticity, induced by a drastic grain size reduction produced by dynamic recrystallization, was proposed by Chokshi and Meyers /6/ to explain the large plastic deformations undergone by shaped charges in copper. Classical superplasticity occurs by grain boundary sliding and the strain rates encountered within the deforming band of Fig. 4 are on the order of $10^{4} \mathrm{~s}^{-1}$. This is also the strain rate within a stretching jet of a shaped charge. Chokshi and Meyers $/ 6 /$ calculated a required grain size of $\leq 0.01 \mu \mathrm{m}$ at this strain rate. The grain sizes observed in Fig. 5(d) are larger, by one order of magnitude, than these. An alternative mechanism for extended stable plastic deformation under continuous dynamic recrystallization is being developed by the authors $/ 14 /$. It is based on a balance between dislocation generation (due to plastic deformation) and dislocation annihilation (due to advance of recrystallizing boundaries) and yields, in its simplest form, a relationship between the steady-state stress and strain rate of the form:

$$
\sigma \propto \dot{\varepsilon}^{m}
$$




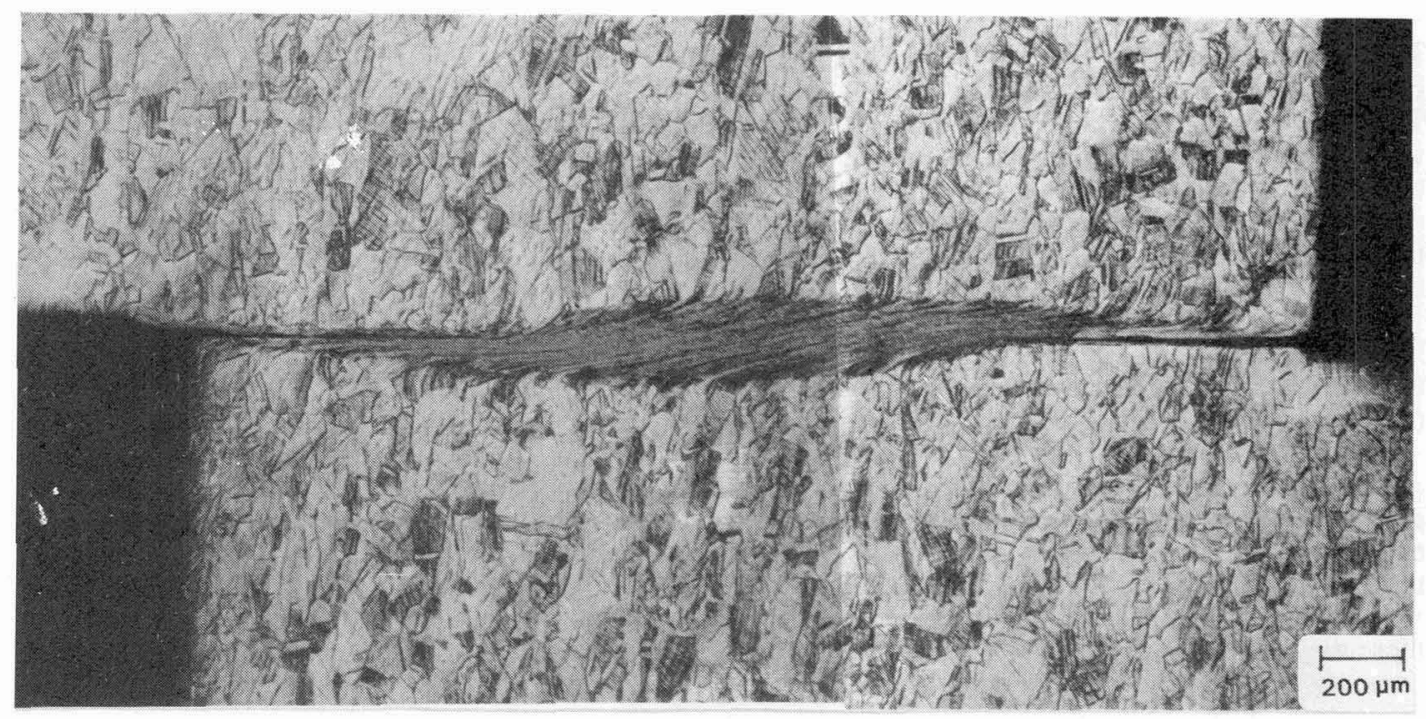

a

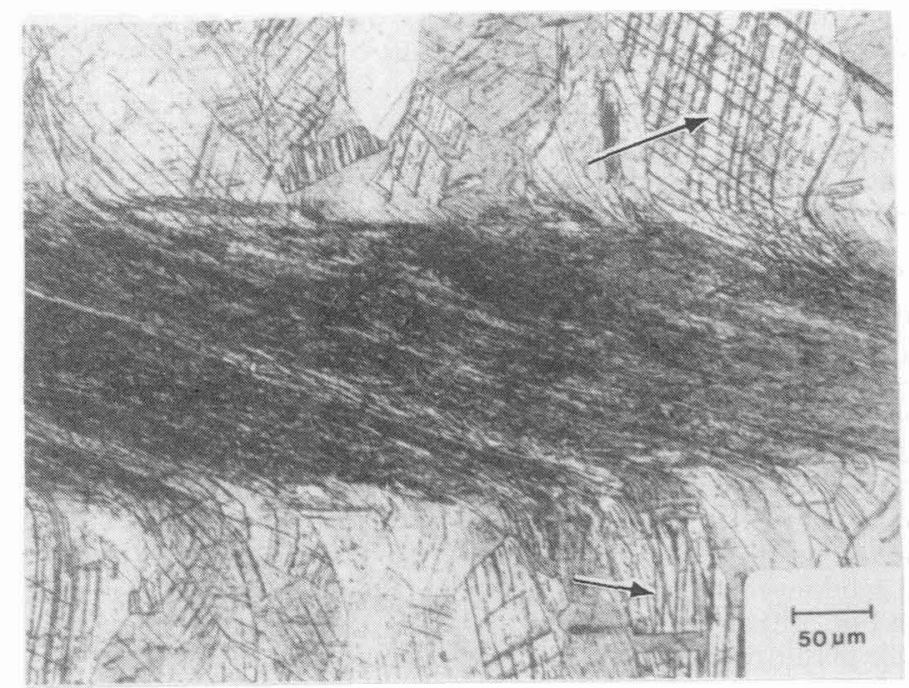

b

Fig. 4 Optical micrographs of region subjected to high strain $(\gamma=5)$ and high strain rate $\left(10^{4} \mathrm{~s}^{-1}\right)$. (a) Specimen cross-section; (b) enlarged view showing mechanical twinning (arrows) and intense shear deformation area. 


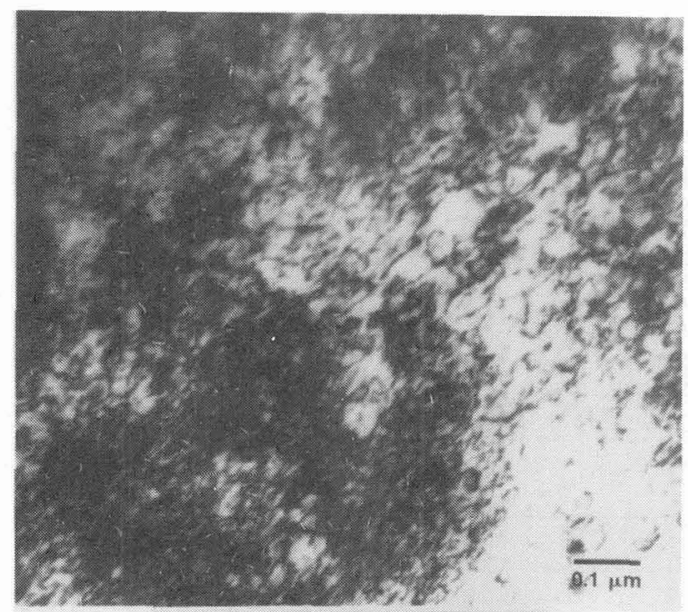

a
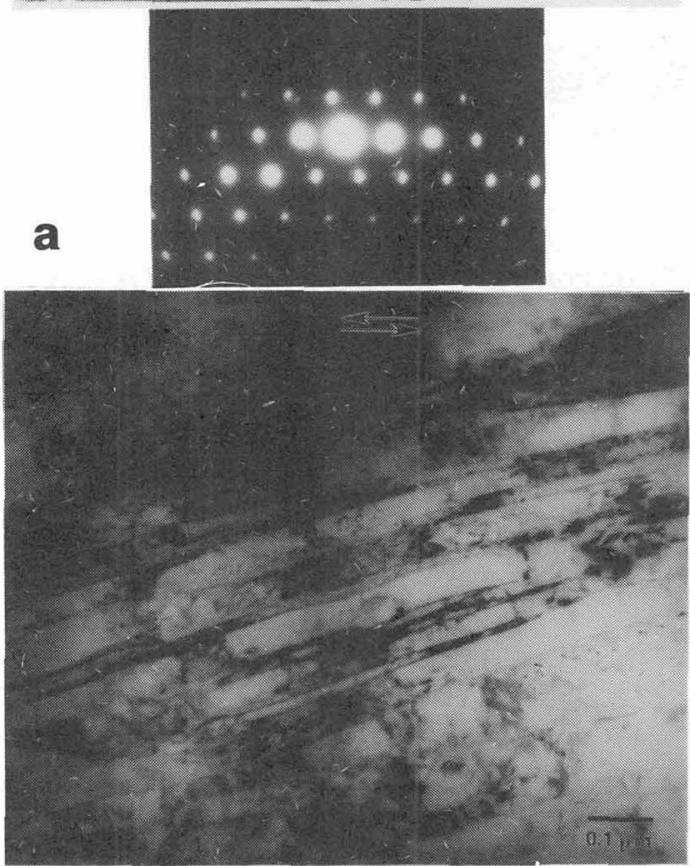

C

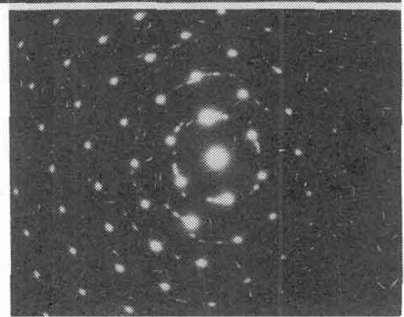

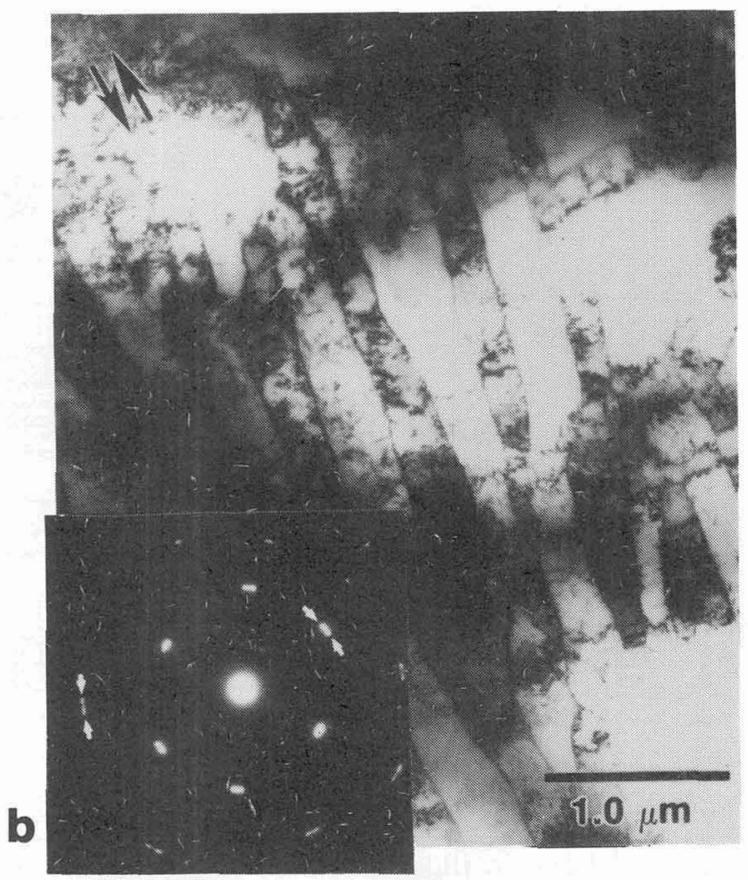

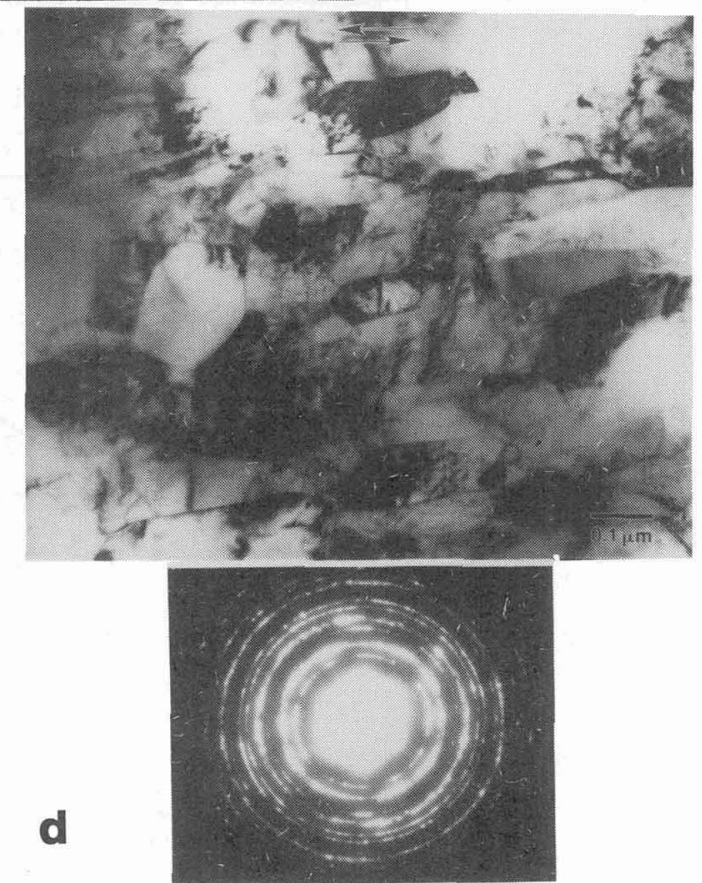

Fig. 5 Transmission electron microscopy and diffraction patterns from specimen subjected to high strain

(a) region outside shear localization area;

(b) region adjacent to shear localization area;

(c) region at onset of shear localization area;

(d) region at center of shear localization area. 
A

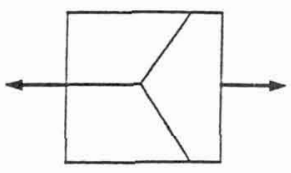

B

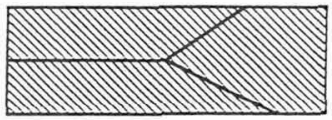

c

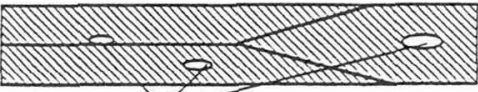

FIRST GENERATIOON RECRYSTALLIZED ĠRAINS

D
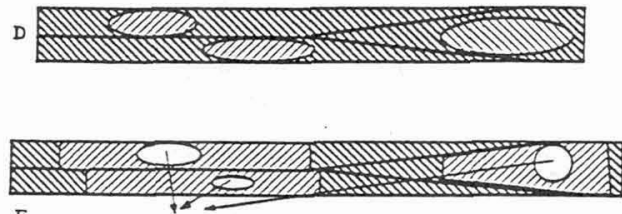

SECOND GENERATION RECR YSTALLIZED GRAINS

Fig. 6 Schematic illustration showing sequence of deformation-recrystallization steps in dynamic recrystallization.

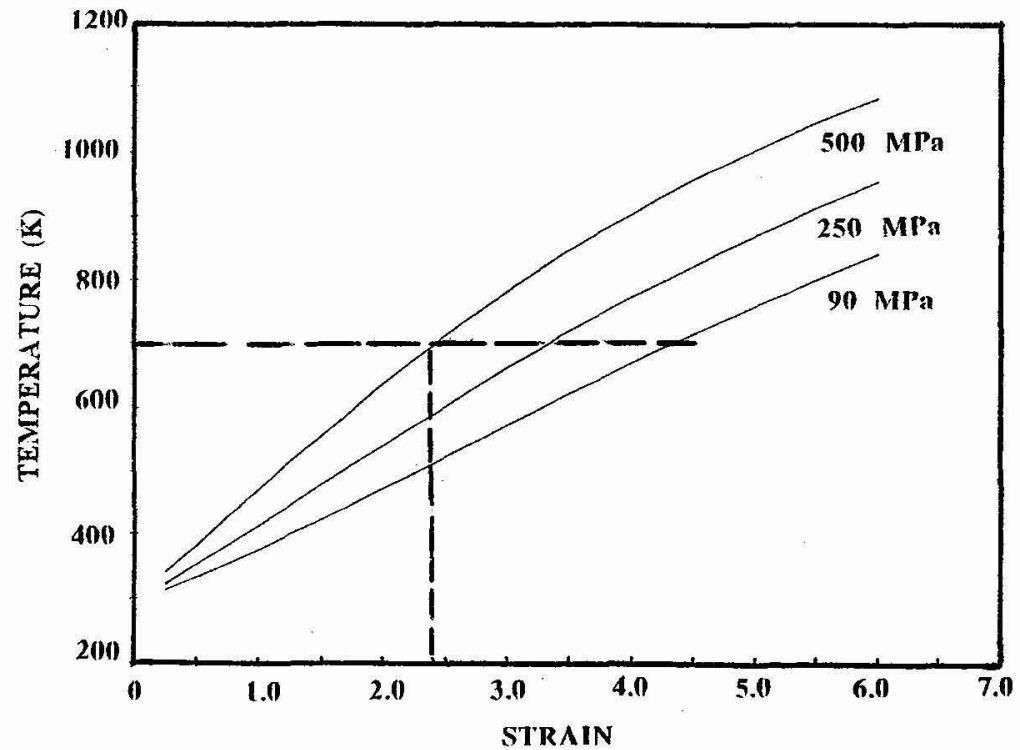

Fig. 7 Temperature as a function of strain for copper with various levels of pre-hardening. 
where the strain-rate sensitivity, $m$, is found to be equal to 0.5 . A value of $m>0.3$ is a necessary requirement for superplasticity. Thus, the microstructure generated by dynamic recrystallization can exhibit extended ductility in tension, and the stretching of shaped charge jets could be attributed, at least partially, to the mechanism described above. The dynamic recrystallization is made possible by the adiabatic rise in temperature as the plastic deformation proceeds. By applying the Johnson-Cook constitutive equation to copper with various initial flow stresses $/ 6,7 /$ the temperature excursions as a function of applied strain (Figure 7) is obtained. The temperature required for dynamic recrystallization, $0.5 \mathrm{~T}_{\mathrm{m}}\left(\mathrm{T}_{\mathrm{m}}=1356 \mathrm{~K}\right)$ is reached at a plastic strain of $\sim 2.4$. These temperatures and strains are marked in Fig. 7. Thus, the rationale provided here for extended stable tensile plasticity in copper under high strain rate conditions is sound.

\section{Acknowledgements}

This research was supported by the U.S. Army Research Office through contracts DAAL03-88-K-0194, DAAL03-89-17-0396, and DAAL03-86-K0169. The use of the facilities of the Center of Excellence for Advanced Materials is gratefully acknowledged. The help of Dr. N. N. Thadhani (CETR - New Mexico Tech) in carrying out the explosive shock experiment is greatly appreciated.

References

1/ GRADY, D., J. Impact Eng., 5 (1987) 285.

21 FRESSENGEAS, C. and MOLINARI, A., Proc. Intl. Conf. Mech. Prop. Mat. at High Strain Rates, Inst. Phys. Conf. Sci., No. 102, p. 57, 1989.

B/ ROMERO, L. A., J. Appl. Phys., 65 (1989) 3006.

14/ JAMET, F., "La Diffraction Instantanée," Report CO 227/84, Institut St. Louis, France, August 1984.

15/ JAMET, F., "Methoden zur Untersuchung der Physikalischen Eigenschaften eines Hohlladungstrahles," Report CO 227/82, Institut St. Louis,France,December 1982.

16/ CHOKSHI, A. H. and MEYERS, M. A., Scripta Met., 24 (1990) 605.

II MEYERS, M. A., MEYER, L. W., BEATTY, J., ANDRADE, U., VECCHIO, K, S., and CHOKSHI, A. H., in Shock-Wave and High-Strain-Rate Phenomena in Materials, eds. M. A. Meyers, L. E. Murr, and K. P. Staudhammer, M. Dekker, in press (1991).

18/ MEYERS, M. A. and MURR, L. E., eds. Shock-Wave and High Strain Rate Phenomena in Metals, Plenum, 1981, pp. 1063, 1074.

91 HARTMAN, K.-H., KUNZE, H.-D., and MEYER, L. W., source cited in Ref. 8, p. 325.

/10/ DE ANGELIS, R. J., and COHEN, J. B., J. Metals, 15 (1963) 681.

/11/ SANDSTROM, R., and LAGNEBORG, R., Acta Met. 23 (1975) 307.

112/ DERBY, B., and ASHBY, M. F., Scripta Met., 21 (1987) 879.

/13/ BAUDELET, B., Metals and Materials, (1974) 117.

/14/ MEYERS, M. A., CHOKSHI, A. H., VECCHIO, K. S., and ANDRADE, U., work in progress, (1991). 